\title{
Reação de genótipos de feijão-caupi revela resistência às coinfecções pelo Cucumber mosaic virus, Cowpea aphid-borne mosaic virus e Cowpea severe mosaic virus
}

\author{
Cláudia Roberta Ribeiro de Oliveira ( $\left.{ }^{1 *}\right)$; Francisco Rodrigues Freire Filho (1); \\ Maria do Socorro da Rocha Nogueira ( $\left.{ }^{1}\right)$; Gislanne Brito Barros ( $\left.{ }^{2}\right)$; Marcelo Eiras (3); \\ Valdenir Queiroz Ribeiro ('); Ângela Celis de Almeida Lopes $\left({ }^{4}\right)$ \\ (') Embrapa Meio-Norte, Av. Duque de Caxias, 5650, 64006-220 Teresina (PI), Brasil. \\ (2) Universidade Federal Rural do Rio de Janeiro (UFRRJ), BR 465, Km 7, 23890-000 Seropédica (RJ), Brasil. \\ (3) Instituto Biológico, Centro de Pesquisa e Desenvolvimento de Sanidade Vegetal, Av. Conselheiro Rodrigues Alves, 1252, \\ Vila Mariana, 04014-002 São Paulo (SP), Brasil. \\ (4) Universidade Federal do Piauí, Campus Socopo, 64049-550 Teresina (PI), Brasil. \\ (*) Autora correspondente: claudiarobertaro@hotmail.com
}

Recebido: 29/jan./2011; Aceito: 20/out./2011

\begin{abstract}
Resumo
O rendimento do feijão-caupi pode ser afetado por diversos fatores, em especial as viroses. As principais espécies de vírus que infectam o feijão-caupi, no Brasil, são: Cucumber mosaic virus (CMV), Cowpea aphid-borne mosaic virus (CABMV), Cowpea severe mosaic virus (CPSMV) e o Bean golden mosaic virus (BGMV). Este trabalho foi realizado em duas etapas e teve como objetivo avaliar a reação de genótipos de feijão-caupi quanto à resistência à infecção simples pelo CMV e mista nas combinações CMV+CABMV, CMV+CPSMV-I e CMV+CABMV+CPSMV-I. Inicialmente, foram incluídos 57 genótipos, sendo três avaliações em gaiolas com tela antiafídeos sob infecção controlada, e uma em condição de campo sob infecção natural. Em seguida, foram selecionados 18 genótipos para serem desenvolvidos em nove ensaios, oito em gaiolas com tela antiafídeos sob infecção controlada, e um em campo sob infecção natural. Nesses ensaios, avaliaram-se os efeitos qualitativos e quantitativos resultantes das infecções. No ensaio de campo, foram avaliados o número de plantas assintomáticas, comprimento de vagem, número de grãos por vagem, massa de cem grãos e produtividade. As coinfecções reduziram a altura da planta e a massa seca. Além disso, nas infecções envolvendo os três vírus ocorreu a morte prematura de alguns genótipos. Os genótipos BR17-Gurguéia, Epace V-96, TE97-309G-9, TE97-309G-22, TE97-309G-24 e Patativa, além de bom comportamento diante das coinfecções virais, têm sementes com padrão comercial, podendo ser empregadas diretamente em programas de melhoramento.
\end{abstract}

Palavras-chave: Vigna unguiculata, resistência a vírus, efeito sinérgico.

\section{Reaction of cowpea genotypes reveals resistance to co-infection by Cucumber mosaic virus, Cowpea aphid-borne mosaic virus and Cowpea severe mosaic virus}

\footnotetext{
Abstract

Many factors can affect the yield of cowpea, especially viruses. The main species of viruses infecting cowpea in Brazil are Cucumber mosaic virus (CMV), Cowpea aphid-borne mosaic virus (CABMV), Cowpea severe mosaic virus (CPSMV) and Cowpea golden mosaic virus (CPGMV). This study aimed to evaluate the reaction of cowpea genotypes for resistance to CMV in single or in co-infections (CMV+CABMV, CMV+CPSMV-I and CMV+CABMV+CPSMV-I), which was accomplished in two steps. Firstly, 57 genotypes were evaluated in four evaluations: three in aphid proof cages with infection under controlled conditions, and one in field-grown plants under natural infection. To perform the second step, we selected 18 genotypes to be conducted in nine trials, with eight under aphid proof cages control infection, and one under natural infection. The qualitative and quantitative effects resulting from infections were evaluated. In the field trial, we assessed the number of asymptomatic plants, pod length, number of grains per pod, 100-grain mass and yield. Mixed infections reduced the plant height and dry weight, and premature death of some genotypes was observed in infections involving the three viruses. The genotypes BR17-Gurguéia, Epace V-96, TE97-309G-9, TE97-309G-22, TE97-309G-24 and Patativa showed the best behavior in relation to the mixed viral infections, presenting seeds with appropriate commercial standard and with potential for using in breeding programs.
} Key words: Vigna unguiculata, virus resistance, synergistic effect. 


\section{INTRODUÇÃO}

Um dos principais fatores limitantes à produção do feijáo-caupi (Vigna unguiculata (L.) Walp.) são as viroses. Dentre os principais vírus que infectam o feijão-caupi, no Brasil, podem ser citados: Cowpea severe mosaic virus (CPSMV) (gênero Comovirus, família Secoviridae); Cowpea aphid-borne mosaic virus (CABMV) (gênero Potyvirus, família Potyviridae); Cucumber mosaic virus (CMV) (gênero Cucumovirus, família Bromoviridae) e Bean golden mosaic virus (BGMV) (gênero Begomovirus, família Geminiviridae) (Beserra Junior et al., 2011; Lima et al., 2005). As infecçóes ocasionadas por vírus podem ocorrer tanto de forma isolada como em coinfecçôes. As coinfecções constituem um dos principais problemas enfrentados pelos melhoristas de plantas, pois genótipos com resistência a um vírus podem ter a resistência suplantada quando coinfectados por dois ou mais vírus (Guerine e Murphy, 1999; García-Cano et al., 2006; Karyeija et al., 2000; Wang et al., 2004). Infecções duplas ou múltiplas podem resultar em uma intensificação da severidade dos sintomas e também no aumento do título viral, sendo esse fenômeno conhecido por sinergismo (Hull, 2002; Martin e Elena, 2009; Wang et al., 2002). $\mathrm{O}$ sinergismo pode afetar diretamente vários parâmetros de crescimento das plantas como altura, massa de matéria seca, rendimento, podendo ser expresso também em graus de severidade de sintomas (Murphy e Bowen, 2006). Os mecanismos envolvidos nas interaçóes sinérgicas ainda não foram totalmente elucidados, porém em muitos casos há o envolvimento da maquinaria de silenciamento pós-transcricional (VoINNET, 2005). Em casos que envolvem a coinfecção por uma espécie de potyvirus, pode haver o incremento da replicação do vírus heterólogo (Pruss et al., 1997) ou uma maior eficiência do movimento intercelular do próprio potyvirus (KaRVEIJEVA et al., 2000). A redução na produção do feijão-caupi, ocasionada por viroses, é mais acentuada quando decorre de infecçóes mistas, frequentemente observadas na natureza (TArwo et al., 2007; Lima et al., 2005).

$\mathrm{O} C M V$, em infecções isoladas, não ocasiona perdas consideráveis na produção do feijão-caupi. No Brasil, verificou-se que essas perdas podem variar de $2,5 \%$ a $5,4 \%$ dependendo da cultivar (Lin et al., 1981a). Entretanto, em coinfecçóes, quando associadas a espécies de Potyvirus, pode haver redução de até $86,4 \%$ da produção (PIORibeiro et al., 1978). A resistência isolada ao CMV e CABMV apresentada por alguns genótipos de feijão-caupi geralmente é perdida quando são coinfectados pelos dois vírus (Barreto e Santos, 1999).

Em estudos realizados no Ceará, detectou-se a ocorrência do CMV com vários graus de incidência e também o complexo CMV+CABMV ocorreu em todas as avaliações com significativos graus de incidência (SAntos et al., 1999).
Devido à importância socioeconômica da cultura do feijāo-caupi principalmente para as regiōes Norte e Nordeste do Brasil, objetivou-se com este trabalho identificar genótipos expressando resistência ao CMV isoladamente e às misturas virais de $\mathrm{CMV}+\mathrm{CABMV}$, CMV+CPSMV-I e CMV+CABMV+CPSMV-I, que possam ser utilizados diretamente ou como parentais em programas de melhoramento, de modo a contribuir para a reduçáo de perdas na qualidade e na quantidade da produção.

\section{MATERIAL E MÉTODOS}

O material genético de feijão-caupi foi composto por 57 genótipos, incluindo cultivares e linhagens brasileiras e introduzidas do International Institute of Tropical Agriculture (IITA).

Os isolados virais do CMV, CABMV e CPSMV-I foram obtidos a partir de plantas de feijão-caupi naturalmente infectadas coletados no município de Teresina, Piauí. O isolamento biológico dos isolados virais foi realizado a partir de inoculaçóes sucessivas com cada um dos vírus, ou seja, para isolar o CMV, utilizou-se a linhagem TE97-309G-3, suscetível ao CMV e resistente ao CABMV. Para isolar o CABMV, utilizou-se a cultivar Pampo que é suscetível ao CABMV e altamente resistente ao CMV, enquanto para isolar o CPSMV-I utilizou-se a linhagem TE97-200-49F. Os isolados foram mantidos separadamente em gaiolas protegidas com tela antiafídeo. A pureza dos isolados foi confirmada por meio de ELISA indireto (Enzyme-Linked Immunosorbent Assay) com antissoros policlonais específicos para o CMV e CABMV e RT-PCR (Reverse Transcription-Polymerase Chain Reaction) com oligonucleotídeos específicos para o CABMV, CPSMV-I e CPSMV-II.

As avaliaçôes das reaçóes dos genótipos aos vírus foram realizadas em duas etapas. Inicialmente, realizaram-se quatro avaliaçôes: três sem delineamento experimental, em gaiolas protegidas com tela antiafídeo e um ensaio em campo em blocos casualizados, com quatro repetiçôes. Em gaiolas, os 57 genótipos foram submetidos à inoculaçáo mecânica com isolados do CMV, CABMV e CPSMV-I, individualmente. Nessa etapa, avaliaram-se os efeitos qualitativos das infecções virais por meio da descrição dos sintomas visuais de acordo com os seguintes critérios: $\mathrm{Bl}$ - bolhosidade; Lc - Lesão clorótica; M - Mosaico; Ml - mosaico leve; Ms - mosaico severo; Ma - Morte apical; Mt - Morte; Ne - Necrose; Rf - redução foliar; Ss - sem sintoma (Vale e Lima, 1994; Rocha et al., 2003). Nessas avaliaçóes, cada genótipo foi representado por dez plantas, sendo oito submetidas à inoculação com o isolado viral e dois com tampão fosfato de sódio $0,01 \mathrm{M}$, $\mathrm{pH}$ 7,5. O tecido foliar infectado foi macerado, em almofariz, na presença de tampão fosfato na proporção de 1,0 
g de tecido foliar para 9,0 $\mathrm{mL}$ de tampão e como abrasivo utilizou-se "Celite".

No ensaio em campo, os genótipos foram expostos à infecção natural. Para aumentar a possibilidade de infecção, foi feito previamente o plantio de genótipos suscetíveis aos vírus CABMV, CPSMV e BGMV para atrair os insetos vetores de vírus e servirem como fonte de inóculo. Após a instalação do ensaio, esses genótipos foram retirados. Nesse ensaio, foi avaliado o número de plantas assintomáticas por parcela, a massa de cem grãos e a produção de grãos da parcela.

Com base nos resultados da primeira avaliação, principalmente do ensaio de campo, foram selecionados 18 genótipos para a segunda etapa de avaliação. Nessa etapa, foram realizados nove ensaios, oito em gaiolas e um em campo. Os genótipos foram submetidos à inoculação com isolados virais nas seguintes combinaçôes: CMV, CMV+CABMV, CMV+CPSMV-I e $\mathrm{CMV}+\mathrm{CABMV}+\mathrm{CPSMV}-\mathrm{I}$. Para cada inoculação, foram realizados, em uma mesma gaiola, dois ensaios, um controle com tampão fosfato de sódio (I-0) e outro com inóculo viral (I-1). Os ensaios foram modelados em delineamento experimental inteiramente casualizado com cinco repetiçōes por genótipo. Cada repetição foi representada por uma planta. Utilizou-se $1,0 \mathrm{~g}$ de tecido foliar infectado para $9 \mathrm{~mL}$ de tampão fosfato e, como abrasivo, foi usado "Celite". Nas inoculaçôes duplas e tripla, 1,0 g de tecido foi composta por quantidades iguais de tecido foliar infectado com cada um dos vírus. As plantas foram submetidas à inoculação seis dias após a semeadura e reinoculadas uma semana após a primeira inoculação. Após as inoculaçôes, as plantas foram lavadas com água corrente para retirada do excesso do inóculo.

Os genótipos foram avaliados quanto aos efeitos qualitativos e quantitativos das infecçôes virais. Os efeitos qualitativos foram avaliados por meio da descrição dos sintomas visuais de acordo VAlE e Lima (1994) e Rocha et al. (2003). Os efeitos quantitativos foram avaliados por meio da medida da altura da planta aos seis e 34 dias após a semeadura; nesta ocasião, o material foi preparado para a obtenção da massa seca. Para a avaliação desse caráter as plantas foram cortadas rente ao solo e colocadas em estufa a $65^{\circ} \mathrm{C}$ por 96 horas e pesadas em seguida.

No ensaio em campo, sob infecção natural, utilizou-se o delineamento em blocos casualizados com quatro repetições. A parcela experimental foi composta de três fileiras de $4,0 \mathrm{~m}$ cada uma, o espaçamento entre fileiras foi de $0,80 \mathrm{~m}$ e de $0,4 \mathrm{~m}$ entre covas dentro da fileira. Foram avaliados: o número de plantas assintomáticas, o comprimento de vagem, o número de grãos por vagem, a massa de cem grãos e a produção por parcela.

Para cada inoculação foi realizada uma análise de variância individual, ou seja, uma para I-0 e outra para I-1, e, em seguida, a análise conjunta, sendo feitos os desdobramentos da soma de quadrados para genótipo dentro de inóculo e para inóculo dentro de genótipo. Para o caráter porcentagem de plantas assintomáticas, os dados foram transformados para arcsen $\sqrt{x}_{\mathrm{x}}$. Em todos os ensaios, antes de se proceder à análise estatística, foi realizada uma análise de resíduo para todos os caracteres, para avaliar a existência de dados discrepantes, verificar a heterocedasticidade de variância e ajustes dos erros a uma distribuição aproximadamente normal.

Os softwares Genes (CruZ, 2007) e SAS (SAS Institute, 2000) foram utilizados para análise de variância e comparação de médias pelo teste Scott-Knott, a $\mathrm{p}<0,05$ de probabilidade, seguindo o metodo proposto por ZimMERMANN (2004).

\section{RESULTADOS E DISCUSSÃO}

\section{Primeira avaliação}

Dos 57 genótipos de feijão-caupi submetidos à inoculação mecânica com os vírus CMV, CABMV e CPSMV-I isoladamente, foram selecionados 18 , os quais são apresentados na tabela 1 .

Entre os genótipos submetidos à inoculação com o isolado de CMV, BR17-Gurguéia, TE97-309G-24, TVu 410 e TVu 966 não manifestaram sintomas de infecçáo viral. Na inoculação mecânica com o isolado de CABMV, nos genótipos IT85F-2687, Patativa, TE97-309G-22,

Tabela 1. Sintomas apresentados pelos genótipos de feijão-caupi submetidos à inoculaçáo mecanicamente com os vírus CMV, CABMV e CPSMV-I em condiçấo de gaiolas protegidas com tela antiafídeos

\begin{tabular}{|c|c|c|c|}
\hline \multirow[b]{2}{*}{ Genótipos } & \multicolumn{3}{|c|}{ Sintomas ( $\left.{ }^{1}\right)$} \\
\hline & CMV ( $\left.{ }^{2}\right)$ & CABMV ( $\left.{ }^{3}\right)$ & CPSMV-I $\left(^{4}\right)$ \\
\hline BR17- Gurguéia & Ss & $\mathrm{M}, \mathrm{BI}, \mathrm{Cl}$ & Ss \\
\hline BRS-Pajeú & $\mathrm{Ml}$ & M & Lc, M, Rf \\
\hline CNC-0434 & $\mathrm{Ml}$ & $\mathrm{M}, \mathrm{BI}, \mathrm{Cl}, \mathrm{Ne}$ & Ss \\
\hline Epace V-96 & Ml & $\mathrm{M}, \mathrm{BI}$ & Ss \\
\hline IT85F-2687 & Ml & Ss & $\mathrm{Ms}, \mathrm{BI}, \mathrm{Cl}, \mathrm{Ne}$ \\
\hline IT93K-452-1 & Ml & Ml & Lc, M, Rf,Ne \\
\hline IT99K-1060 & Ml & $\mathrm{Ml}$ & $\mathrm{Mt}$ \\
\hline Pampo & Ml & $\mathrm{M}, \mathrm{BI}$ & Lc, M, Rf \\
\hline Patativa & Ml & Ss & Ss \\
\hline TE97-200-49F & $\mathrm{Ml}$ & $\mathrm{M}, \mathrm{BI}$ & $\mathrm{M}, \mathrm{BI}, \mathrm{Cl}$ \\
\hline TE97-309G-22 & Ml & Ss & Ss \\
\hline TE97-309G-24 & Ss & M & Ss \\
\hline TE97-309G-9 & $\mathrm{Ml}$ & Ss & Ss \\
\hline TVu 379 & $\mathrm{Ml}$ & Ss & Ss \\
\hline TVu 382 & Ml & Ss & Ss \\
\hline TVu 3961 & Ml & $\mathrm{M}, \mathrm{BI}$ & Ss \\
\hline TVu 410 & Ss & Ss & Lc, M, Rf,Ne \\
\hline TVu 966 & Ss & Ss & Ss \\
\hline
\end{tabular}

(') M: Mosaico. Ml: Mosaico leve. Ms: Mosaico severo. Cl: Clorose. Lc: Lesăo clorótica. Rf: Reduçâo foliar. Ne: Necrose. Ma: Morte apical. Mt: Morte. Ss: Sem sintomas. $\left({ }^{2}\right)$ Cucumber mosaic virus (CMV). $\left({ }^{3}\right)$ Cowpea aphid-borne mosaic virus (CABMV). $\left.{ }^{4}\right)$ Cowpea severe mosaic virus (CPSMV-I). 
TE97-309G-9, TVu 379, TVu 382, TVu 410 e TVu 966 não ocorreram sintomas. Dentre os genótipos submetidos à inoculação com isolado do CPSMV-I, em BR 17-Gurguéia, CNC-0434, Epace V-96, Patativa, TE97309G-22, TE97-309G-24, TE97-309G-9, TVu 379, TVu 382, TVu 3961 e TVu 966 não se observaram sintomas. Apenas na linhagem TVu 966 não houve sintomas de nenhum dos três vírus. A resistência do genótipo TVu 410 ao CMV já havia sido detectada por Mrн et al. (1991), e a dos genótipos TVu 379, TVu 382, e TVu 966 ao CAMBV e ao CPSMV por LiMA et al. (1986).

\section{Segunda avaliação}

\section{Ensaios sob inoculaçấo viral controlada}

$\mathrm{Na}$ avaliação de altura de planta aos 34 dias após a semeadura (L2), nas análises em que todos os genótipos foram submetidos à inoculaçáo com I-0 e I-1, os ensaios com I-0, considerando todas as combinaçóes virais avaliadas, os genótipos Pampo, TE97-200-49F, BR17-Gurguéia e IT93K-452-1 foram os que tiveram as maiores alturas. Nos ensaios com I-1, para L2, na inoculação com CMV, sobressaíram-se os genótipos TE97-309G-22 $(37,84 \mathrm{~cm})$ e TE97-200-49F $(37,18 \mathrm{~cm})$, não diferindo estatisticamente entre si. $\mathrm{Na}$ inoculação com isolados de CMV+CABMV, destacou-se a cultivar Pampo $(41,66 \mathrm{~cm})$, superando estatisticamente os demais genótipos. $\mathrm{Na}$ avaliação com os inóculos de CMV+CPSMV-I, observou-se a maior média no genótipo BR17-Gurguéia $(35,26 \mathrm{~cm})$, o qual diferiu estatisticamente dos demais. $\mathrm{Na}$ inoculação com CMV+CABMV+CPSMV-I, os genótipos BR17-Gurguéia $(30,81 \mathrm{~cm})$, TVu $3961(28,44 \mathrm{~cm})$ e CNC-0434 $(25,30 \mathrm{~cm})$ tiveram as maiores alturas de planta e diferiram dos demais genótipos (Tabela 2).

Nos ensaios com I-1, os genótipos BR17-Gurguéia e Epace V-96 se destacaram, mas nenhum ficou entre os de maior altura de planta em todos os quatro ensaios (Tabela 2). Nas análises referentes à inoculação de um mesmo genótipo com I-0 e com I-I, em L2, na inoculação CMV, observou-se que entre I-0 e I-1 náo houve diferença significativa em nove genótipos, em seis as plantas em I-1 tiveram altura maior que em I- 0 , enquanto em três genótipos houve redução significativa de altura. $\mathrm{Na}$ inoculação com isolados de $\mathrm{CMV}+\mathrm{CABMV}$, seis genótipos não diferiram significativamente; em três, as plantas em I-1 foram maiores que em I-0 e nove genótipos tiveram redução significativa de altura de planta. $\mathrm{Na}$ inoculaçấo com CMV+CPSMV-I, em sete genótipos não houve diferença significativa, em quatro, as plantas em I-1 foram maiores que em I-0 e em oito genótipos a altura de planta foi reduzida significativamente. $\mathrm{Na}$ inoculação com a combinação de isolados CMV+CABMV+CPSMV-I, quatro genótipos não diferiram significativamente de altura de planta; em dez, houve reduçáo significativa e em quatro, as plantas morreram antes de 20 dias após a semeadura (Tabela 2).

Nos ensaios com I-0, considerando as quatro combinaçôes virais, a maior massa seca foi observada nos genótipos Pampo, Patativa e BRS-Pajeú (Tabela 3). Nos ensaios com I-1, para a massa seca, na inoculação com CMV, os genótipos TE97-200-49F $(2,86 \mathrm{~cm})$, IT99K-1060 $(2,68 \mathrm{~cm})$ e BRS-Pajeú $(2,68 \mathrm{~cm})$ tiveram os maiores resultados e superaram significativamente os outros genótipos (Tabela 3). Na inoculação com os isolados de CMV+CABMV, a maior massa seca foi constatada nos genótipos TVu 379 (3,00 cm) e TVu 966 (2,96 $\mathrm{cm}$ ) e diferiram estatisticamente dos demais genótipos. $\mathrm{Na}$ inoculação com CMV+CPSMV-I, as maiores médias foram apresentadas pelos genótipos Epace V-96 (2,74 cm), TE97-309G-9 (2,78 cm) e CNC-0434 $(2,76 \mathrm{~cm})$, os quais foram significativamente semelhantes a outros cinco genótipos. Com a combinação dos isolados dos três vírus, CMV+CABMV+CPSMV-I, nos genótipos BR17-Gurguéia $(1,84 \mathrm{~cm})$ e TE97-309G-9 $(1,90 \mathrm{~cm})$ notaram-se significativamente os maiores valores.

Nas análises da inoculação de um mesmo genótipo com I-0 e com I-I, para a massa seca da parte área aos 34 dias, na inoculação com o isolado de $\mathrm{CMV}$, não foi detectada diferença significativa entre I-0 e I-1 em 12 genótipos; em três as plantas em I-1 tiveram maior massa seca que em I-0, e em três genótipos, houve reduçáo significativa. $\mathrm{Na}$ inoculação com a combinação $\mathrm{CMV}+\mathrm{CABMV}$, não houve diferença significativa em 13 genótipos e em cinco, a redução da massa seca foi significativa. $\mathrm{Na}$ inoculação com CMV+CPSMV-I, em oito genótipos não houve diferença significativa, em três, a massa seca das plantas em I-1 superaram o das plantas em I-0 e em sete genótipos houve redução significativa. Infecçóes virais mistas têm implicaçóes biológicas importantes, podendo ser sinérgicas ou antagônicas. Na literatura, há trabalhos mostrando efeitos sinérgicos e antagônicos de infecçóes virais duplas em diversos patossistemas (HulL, 2002; Wang et al., 2002; García-Cano et al., 2006; Martín e Elena, 2009). Em feijão-caupi, há poucos trabalhos publicados abordando este tema (Pio-Ribeiro et al., 1978; Kareem e Taiwo, 2007; Tarwo et al., 2007), porém as doenças severas, devido a efeitos sinérgicos causados por infecçôes virais duplas, sempre estão associadas à presença de um potyvirus (Kareem e Taiwo, 2007; Pio-Ribeiro et al., 1978). Na inoculação com os isolados dos três vírus, $\mathrm{CMV}+\mathrm{CABMV}+\mathrm{CPSMV-I}$, em dois genótipos não houve diferença significativa na massa seca; em 12 a redução foi significativa e quatro haviam morrido antes de 20 dias após a semeadura (Tabela 3).

A não ocorrência de diferença na altura da planta ou na massa seca entre as inoculaçôes com I-0 e com I-1, ou a maior altura em I-1, em um mesmo genótipo indicam que este não foi afetado ou foi afetado muito pouco pelo vírus ou pela associação de vírus. As interações sinérgicas 
Tabela 2. Médias, média geral e coeficiente de variação da altura de plantas $(\mathrm{cm})$ de genótipos de feijão-caupi submetidos à inoculação com tampão fosfato de sódio e com extratos de plantas infectadas com isolado do CMV, CMV + CABMV, CMV + CPSMV-I e CMV + CABMV + CPSMV-I obtidas em avaliaçôes realizadas aos 34 dias (L2) após a semeadura

\begin{tabular}{|c|c|c|c|c|c|c|c|c|c|c|c|c|c|c|c|c|}
\hline \multirow{3}{*}{$\begin{array}{l}\text { Genótipos } \\
\text { BR17-Gurguéia }\end{array}$} & \multicolumn{4}{|c|}{ CMV } & \multicolumn{4}{|c|}{ CMV + CABMV } & \multicolumn{4}{|c|}{ CMV + CPSMV-I } & \multicolumn{4}{|c|}{ CMV+CABMV+CPSMV-I } \\
\hline & \multicolumn{2}{|c|}{ I-0 } & \multicolumn{2}{|c|}{ I-1 } & \multicolumn{2}{|c|}{ I-O } & \multicolumn{2}{|c|}{ I-1 } & \multicolumn{2}{|c|}{$1-0$} & \multicolumn{2}{|c|}{ I-1 } & \multicolumn{2}{|c|}{ I-0 } & \multicolumn{2}{|c|}{ I-1 } \\
\hline & 29,22 & $\mathrm{Ca}$ & 30,92 & $\mathrm{Da}$ & 38,07 & $\mathrm{Ba}$ & 31,81 & $\mathrm{Bb}$ & 37,66 & $\mathrm{Aa}$ & 35,26 & $A b$ & 38,64 & $\mathrm{Aa}$ & 30,81 & $A b$ \\
\hline Epace V-96 & 31,22 & $\mathrm{Cb}$ & 34,92 & $\mathrm{Ba}$ & 29,00 & $\mathrm{Ca}$ & 28,98 & $\mathrm{Ca}$ & 24,18 & $\mathrm{Db}$ & 27,48 & $\mathrm{Ca}$ & 19,14 & $\mathrm{Da}$ & 19,94 & $\mathrm{Ba}$ \\
\hline Patativa & 25,28 & $\mathrm{Db}$ & 32,41 & $\mathrm{Ca}$ & 28,78 & $\mathrm{Ca}$ & 15,72 & $G b$ & 20,48 & $\mathrm{Fa}$ & 18,24 & $\mathrm{~Gb}$ & 25,22 & $\mathrm{Ba}$ & 16,90 & $\mathrm{Bb}$ \\
\hline TE97-309G-22 & 34,44 & $\mathrm{Bb}$ & 37,84 & $\mathrm{Aa}$ & 30,91 & $\mathrm{Ca}$ & 24,90 & $\mathrm{~Eb}$ & 24,11 & $\mathrm{Da}$ & 26,10 & $\mathrm{Da}$ & 22,70 & $\mathrm{Ca}$ & 12,65 & $\mathrm{Cb}$ \\
\hline TE97-309G-9 & 24,28 & $\mathrm{Da}$ & 26,62 & $\mathrm{Ea}$ & 30,12 & $\mathrm{Ca}$ & 27,23 & $\mathrm{Db}$ & 22,08 & $\mathrm{Ea}$ & 20,92 & $\mathrm{Fa}$ & 24,70 & $\mathrm{Ba}$ & 20,00 & $\mathrm{Bb}$ \\
\hline TVu 379 & 26,80 & $\mathrm{Da}$ & 23,30 & $\mathrm{Fb}$ & 20,40 & Ea & 19,84 & $\mathrm{Fa}$ & 21,50 & $\mathrm{Ea}$ & 23,28 & $\mathrm{Ea}$ & 19,60 & $\mathrm{Da}$ & 16,80 & $\mathrm{Ba}$ \\
\hline TVu 382 & 27,86 & $\mathrm{Da}$ & 26,41 & $\mathrm{Ea}$ & 28,52 & $\mathrm{Ca}$ & 23,84 & $\mathrm{~Eb}$ & 24,96 & $\mathrm{Da}$ & 21,35 & $\mathrm{Fb}$ & 22,64 & $\mathrm{Ca}$ & 17,02 & $\mathrm{Bb}$ \\
\hline TVu 3961 & 22,46 & $\mathrm{Ea}$ & 18,92 & Gb & 29,66 & $\mathrm{Cb}$ & 32,82 & $\mathrm{Ba}$ & 30,02 & $\mathrm{Ca}$ & 26,40 & $\mathrm{Db}$ & 28,58 & $\mathrm{Ba}$ & 28,44 & $\mathrm{Aa}$ \\
\hline TVu 966 & 26,38 & $\mathrm{Db}$ & 30,23 & $\mathrm{Da}$ & 21,50 & Ea & 21,54 & $\mathrm{Fa}$ & 27,76 & $\mathrm{Ca}$ & 28,82 & $\mathrm{Ca}$ & 25,60 & $\mathrm{Ba}$ & 21,86 & $\mathrm{Bb}$ \\
\hline CNC-0434 & 33,23 & $\mathrm{Ba}$ & 32,14 & $\mathrm{Ca}$ & 18,50 & $\mathrm{Fb}$ & 22,48 & $\mathrm{Fa}$ & 22,44 & $\mathrm{~Eb}$ & 26,48 & $\mathrm{Da}$ & 25,20 & $\mathrm{Ba}$ & 25,30 & $\mathrm{Aa}$ \\
\hline IT85F-2687 & 21,80 & Eb & 29,35 & $\mathrm{Da}$ & 25,54 & $\mathrm{Da}$ & 23,62 & $\mathrm{Ea}$ & 18,28 & Ga & 11,59 & $\mathrm{lb}$ & 21,78 & $\mathrm{Ca}$ & 11,60 & $\mathrm{Cb}$ \\
\hline TE97-200-49F & 37,00 & $\mathrm{Aa}$ & 37,18 & $\mathrm{Aa}$ & 43,20 & $\mathrm{Aa}$ & 34,71 & $\mathrm{Bb}$ & 29,02 & $\mathrm{Cb}$ & 31,18 & $\mathrm{Ba}$ & 38,72 & A & Mt & \\
\hline TVu 410 & 24,78 & $\mathrm{Da}$ & 26,04 & Ea & 27,31 & $\mathrm{Da}$ & 22,03 & $\mathrm{Fb}$ & 16,10 & Ga & 14,90 & $\mathrm{Ha}$ & 26,30 & B & Mt & \\
\hline IT93K-452-1 & 30,06 & $\mathrm{Ca}$ & 29,56 & $\mathrm{Da}$ & 36,22 & $\mathrm{Ba}$ & 27,63 & $\mathrm{Db}$ & 29,28 & $\mathrm{Ca}$ & 20,75 & $\mathrm{Fb}$ & 28,18 & $\mathrm{Ba}$ & 14,70 & $\mathrm{Cb}$ \\
\hline IT99K-1060 & 19,92 & $\mathrm{Ea}$ & 20,54 & Ga & 16,94 & $\mathrm{Fa}$ & 19,42 & $\mathrm{Fa}$ & 20,60 & $\mathrm{Fa}$ & 7,00 & $\mathrm{Jb}$ & 18,20 & $\mathrm{D}$ & Mt & \\
\hline Pampo & 37,10 & $\mathrm{Aa}$ & 33,82 & $\mathrm{Bb}$ & 43,26 & $\mathrm{Aa}$ & 41,66 & $\mathrm{Aa}$ & 33,22 & $\mathrm{Ba}$ & 29,58 & $\mathrm{Cb}$ & 37,56 & A & Mt & \\
\hline TE97-309G-24 & 21,64 & Ea & 22,40 & $\mathrm{Fa}$ & 22,40 & Eb & 25,80 & $\mathrm{Da}$ & 17,76 & Gb & 21,34 & $\mathrm{Fa}$ & 22,86 & $\mathrm{Ca}$ & 18,06 & $\mathrm{Bb}$ \\
\hline BRS-Pajeú & 26,36 & $\mathrm{Db}$ & 33,12 & $\mathrm{Ca}$ & 29,84 & $\mathrm{Ca}$ & 24,09 & $\mathrm{~Eb}$ & 19,44 & $\mathrm{Fa}$ & 17,72 & $\mathrm{Ga}$ & 26,80 & $\mathrm{Ba}$ & 16,50 & $\mathrm{Bb}$ \\
\hline Média & 27,77 & & 29,21 & & 28,90 & & 26,01 & & 24,38 & & 22,69 & & 26,25 & & 20,61 & \\
\hline CV (\%) & 7,91 & & & & 7,50 & & 8,36 & & 6,93 & & 6,85 & & 10,05 & & 12,00 & \\
\hline
\end{tabular}

Médias na vertical seguidas da mesma letra maiúscula năo diferem estatisticamente pelo teste Scott-Knott (p>0,05). Para uma mesma característica, médias na horizontal seguidas pela mesma letra minúscula não diferem estatisticamente pelo teste " $F$ " ( $p>0,05$ ). I- 0 : Plantas de feijão-caupi submetidas à inoculação com tampão fosfato de sódio. I-1: Plantas de feijăo-caupi submetidas à inoculaçáo com extratos de plantas infectadas com isolado de CMV e com a combinaçáo de isolados do CMV+CAMV, CMV+CPSMV-I e CMV+CABMV+CPSMV-I. L2- Leitura realizada aos 34 dias após a semeadura. Mt: Morte das plantas.

Tabela 3. Médias, média geral e coeficiente de variação da matéria seca $(\mathrm{g})$ de genótipos de feijão-caupi submetidos à inoculação com tampão fosfato de sódio e com extratos de plantas infectadas com isolado do CMV, CMV+CABMV, CMV+CPSMV-I e CMV+CABMV+CPSMV-I obtidas aos 34 dias após inoculação

\begin{tabular}{|c|c|c|c|c|c|c|c|c|c|c|c|c|c|c|c|c|}
\hline \multirow{3}{*}{$\begin{array}{l}\text { Genótipos } \\
\text { BR17-Gurguéia }\end{array}$} & \multicolumn{4}{|c|}{ CMV } & \multicolumn{4}{|c|}{$\mathrm{CMV}+\mathrm{CABMV}$} & \multicolumn{4}{|c|}{ CMV+CPSMV-I } & \multicolumn{4}{|c|}{ CMV+CABMV+CPSMV-I } \\
\hline & \multicolumn{2}{|c|}{ I-O } & \multicolumn{2}{|c|}{ I-1 } & \multicolumn{2}{|c|}{ I-O } & \multicolumn{2}{|c|}{ I-1 } & \multicolumn{2}{|c|}{ I-O } & \multicolumn{2}{|c|}{ I-1 } & \multicolumn{2}{|c|}{ I-O } & \multicolumn{2}{|c|}{ I-1 } \\
\hline & 1,24 & $\mathrm{Ea}$ & 1,33 & $\mathrm{Da}$ & 2,14 & $\mathrm{Ba}$ & 2,22 & $\mathrm{Ba}$ & 2,46 & $\mathrm{Ba}$ & 2,53 & $\mathrm{Aa}$ & 2,26 & $\mathrm{Ba}$ & 1,84 & $A b$ \\
\hline Epace V-96 & 2,18 & $\mathrm{Ba}$ & 2,18 & $\mathrm{Ba}$ & 1,46 & $\mathrm{Ba}$ & 1,22 & $\mathrm{Ca}$ & 2,60 & $\mathrm{Ba}$ & 2,74 & $\mathrm{Aa}$ & 1,20 & $\mathrm{Da}$ & 0,62 & $\mathrm{Cb}$ \\
\hline Patativa & 2,20 & $\mathrm{Ba}$ & 1,92 & $\mathrm{Ca}$ & 2,28 & $\mathrm{Ba}$ & 0,26 & $\mathrm{Db}$ & 2,44 & $\mathrm{Ba}$ & 2,32 & $\mathrm{Ba}$ & 2,42 & $\mathrm{Ba}$ & 0,86 & $\mathrm{Cb}$ \\
\hline TE97-309G-22 & 2,68 & $\mathrm{Aa}$ & 1,94 & $\mathrm{Cb}$ & 1,78 & $\mathrm{Ba}$ & 1,51 & $\mathrm{Ca}$ & 2,24 & $\mathrm{Ca}$ & 2,09 & $\mathrm{Ba}$ & 1,14 & $\mathrm{Da}$ & 0,40 & $\mathrm{Cb}$ \\
\hline TE97-309G-9 & 2,52 & $\mathrm{Aa}$ & 2,48 & $\mathrm{Ba}$ & 2,66 & $\mathrm{Aa}$ & 2,32 & $\mathrm{Ba}$ & 2,78 & $\mathrm{Aa}$ & 2,78 & $\mathrm{Aa}$ & 1,42 & $\mathrm{Da}$ & 1,90 & $\mathrm{Aa}$ \\
\hline TVu 379 & 1,76 & $\mathrm{Ca}$ & 1,54 & $\mathrm{Da}$ & 3,06 & $\mathrm{Aa}$ & 3,00 & $\mathrm{Aa}$ & 2,08 & $\mathrm{Cb}$ & 2,56 & $\mathrm{Aa}$ & 1,66 & $\mathrm{Ca}$ & 1,02 & $\mathrm{Bb}$ \\
\hline TVu 382 & 2,28 & $\mathrm{Ba}$ & 2,04 & $\mathrm{Ca}$ & 2,10 & $\mathrm{Ba}$ & 1,36 & $\mathrm{Cb}$ & 2,78 & $\mathrm{Aa}$ & 2,43 & $A b$ & 1,38 & $\mathrm{Da}$ & 1,24 & $\mathrm{Ba}$ \\
\hline TVu 3961 & 2,10 & $\mathrm{Ba}$ & 1,98 & $\mathrm{Ca}$ & 2,28 & $\mathrm{Ba}$ & 2,16 & $\mathrm{Ba}$ & 2,32 & $\mathrm{Cb}$ & 2,64 & $\mathrm{Aa}$ & 1,62 & $\mathrm{Ca}$ & 0,90 & $\mathrm{Cb}$ \\
\hline TVu 966 & 2,24 & $\mathrm{Ba}$ & 2,02 & $\mathrm{Ca}$ & 3,34 & $\mathrm{Aa}$ & 2,96 & $\mathrm{Aa}$ & 2,56 & $\mathrm{Ba}$ & 2,62 & $\mathrm{Aa}$ & 1,68 & $\mathrm{Ca}$ & 1,26 & $\mathrm{Bb}$ \\
\hline CNC-0434 & 2,13 & $\mathrm{Ba}$ & 1,88 & $\mathrm{Ca}$ & 2,12 & $\mathrm{Ba}$ & 1,70 & $\mathrm{Ca}$ & 2,44 & $\mathrm{Bb}$ & 2,76 & $\mathrm{Aa}$ & 1,60 & $\mathrm{Ca}$ & 1,18 & $\mathrm{Bb}$ \\
\hline IT85F-2687 & 2,84 & $\mathrm{Aa}$ & 2,28 & $\mathrm{Bb}$ & 2,56 & $\mathrm{Aa}$ & 2,19 & $\mathrm{Ba}$ & 2,00 & $\mathrm{Ca}$ & 0,42 & Eb & 1,84 & $C$ & $\mathrm{Mt}$ & \\
\hline TE97-200-49F & 2,12 & $\mathrm{Bb}$ & 2,86 & $\mathrm{Aa}$ & 2,86 & $\mathrm{Aa}$ & 1,92 & $\mathrm{Bb}$ & 2,48 & $\mathrm{Ba}$ & 1,76 & $\mathrm{Cb}$ & 1,57 & $C$ & Mt & \\
\hline TVu 410 & 1,52 & $\mathrm{Da}$ & 1,69 & $\mathrm{Da}$ & 1,86 & $\mathrm{Ba}$ & 1,42 & $\mathrm{Ca}$ & 2,06 & $\mathrm{Ca}$ & 1,00 & $\mathrm{Db}$ & 1,84 & $C$ & Mt & \\
\hline IT93K-452-1 & 1,60 & $\mathrm{Db}$ & 2,04 & $\mathrm{Ca}$ & 2,24 & $\mathrm{Ba}$ & 0,94 & $\mathrm{Cb}$ & 2,89 & $\mathrm{Aa}$ & 0,62 & $\mathrm{~Eb}$ & 2,12 & $B$ & $\mathrm{Mt}$ & \\
\hline IT99K-1060 & 2,48 & $\mathrm{Aa}$ & 2,68 & $\mathrm{Aa}$ & 2,04 & $\mathrm{Ba}$ & 1,59 & $\mathrm{Ca}$ & 2,43 & $\mathrm{Ba}$ & 0,22 & $\mathrm{Fb}$ & 1,57 & $C$ & Mt & \\
\hline Pampo & 1,98 & $\mathrm{Cb}$ & 2,42 & $\mathrm{Ba}$ & 2,62 & $\mathrm{Aa}$ & 2,10 & $\mathrm{Ba}$ & 2,86 & $\mathrm{Aa}$ & 1,26 & $\mathrm{Db}$ & 3,05 & $A$ & Mt & \\
\hline TE97-309G-24 & 2,67 & $\mathrm{Aa}$ & 2,27 & $\mathrm{Bb}$ & 2,26 & $\mathrm{Ba}$ & 1,18 & $\mathrm{Ca}$ & 2,20 & $\mathrm{Ca}$ & 2,25 & $\mathrm{Ba}$ & 1,78 & $\mathrm{Ca}$ & 0,68 & $\mathrm{Cb}$ \\
\hline BRS-Pajeú & 2,82 & $\mathrm{Aa}$ & 2,68 & $\mathrm{Aa}$ & 2,60 & $\mathrm{Aa}$ & 1,92 & $\mathrm{Bb}$ & 2,12 & $\mathrm{Ca}$ & 2,13 & $\mathrm{Ba}$ & 2,29 & $\mathrm{Ba}$ & 0,50 & $\mathrm{Cb}$ \\
\hline Média & 2,19 & & 2,12 & & 2,35 & & 1,78 & & 2,43 & & 1,95 & & 1,80 & & 0,98 & \\
\hline CV (\%) & 10,83 & & 12,25 & & 21,22 & & 26,54 & & 8,93 & & 10,54 & & 18,93 & & 33,34 & \\
\hline
\end{tabular}

Médias na vertical seguidas da mesma letra nẫo diferem pelo teste de Scott-Knott ( $>0,05)$. ${ }^{* *} \mathrm{e}^{*}$ : significativo a $1 \%$ e $5 \%$ de probabilidade respectivamente. Para uma mesma característica, médias na horizontal seguidas pela mesma letra minúscula nấo diferem estatisticamente pelo teste "F" ( $\mathrm{p}>0,05)$. I-0: Plantas de feijăo-caupi inoculadas com tampáo fosfato de sódio. I-1: Plantas de feijāo-caupi submetidas à inoculação com extratos de plantas infectadas com isolado de CMV e com a combinaçấo de isolados do CMV+CAMV, CMV+CPSMV-I e CMV+CABMV+CPSMV-I. MS: Matéria seca. Mt: Morte das plantas. 
e antagônicas podem causar consequências biológicas e epidemiológicas imprevisíveis. Normalmente, na interação sinérgica, um ou mais vírus podem se replicar na hospedeira, aumentando a severidade dos sintomas. Em contraste, na interação antagônica apenas um dos vírus é beneficiado, e sua presença resulta na completa ausência ou menor atividade do outro vírus (Syller, 2011). Desse modo, os genótipos com o menor número de diferenças significativas entre as inoculaçôes com I-0 e com I- 1 , com os diferentes inóculos virais na altura de planta e na massa seca aos 34 dias após a semeadura foram Epace V-96, TE97-309G-9, TVu 379, TVu 3961, TVu 966, CNC0434 e TE97-309G-24.

\section{Sintomas visuais}

O efeito da infecção com CMV foi apenas de mosaico leve para a maioria dos genótipos (Tabela 4). A inoculação induziu sintomas de infecção na maioria dos genótipos avaliados, com exceçấo do BR17-Gurguéia, TVu 966, TE97-309G-24 e TVu 410. Entretanto, os sintomas desapareceram entre duas e três semanas após a inoculação. O genótipo TVu 410 também foi identificado por Мıн et al. (1991) como altamente resistente ao CMV. No que se refere ao desaparecimento dos sintomas nas plantas, resultados semelhantes foram descritos por Lin et al. (1981a,b) e Mir et al. (1991). Na linhagem IT85F-2687 houve suscetibilidade ao isolado de CMV usado no presente estudo, porém em estudos realizados por RocHA et al. (2003) a mesma linhagem foi identificada como imune. Na cultivar CNC-0434 ocorreu suscetibilidade ao isolado de CMV corroborando com os resultados obtidos por Vale e Lima (1994).

As inoculaçóes mistas envolvendo o $\mathrm{CMV}+\mathrm{CABMV}$ permitiram identificar seis genótipos resistentes: Patativa, TE97-309G-22, TE97-309G-9, TVu 382, TVu 966 e IT85F-2687 (Tabela 4). Na linhagem TVu 382, referida na literatura como imune ao CABMV (LiMA et al., 1986), ocorreu o mesmo comportamento quando submetidas à inoculação com a combinação CMV+CABMV. RocHA et al. (2003) constataram que a linhagem IT85F-2687 foi imune aos dois vírus isoladamente, entretanto, quando submetidas à inoculaçáo com a combinação dos dois isolados, foi suscetível, indicando que houve sinergismo entre os vírus. Os sintomas constatados na cultivar CNC0434 foram semelhantes aos verificados por VALE e LimA (1994).

$\mathrm{Na}$ infecção mista com CMV+CPSMV-I houve predominância de genótipos com mosaico leve (Ml). O comportamento da cultivar CNC-0434 Ml foi semelhante ao observado por Vale e Lima (1994). Nos genótipos BR17Gurguéia, TVu 966 e TE97-309G-24 não ocorreram sintomas com a inoculação com essa combinação de isolados virais. Na infecção com CMV+CABMV+CPSMV-I, identificou-se apenas os genótipos Patativa, TE 97-309G-22 e TE 97-309G-9 náo havendo sintomas. Esse resultado, de certo modo, náo era esperado, uma vez que nos mesmos genótipos observou-se $\mathrm{Ml}$ quando foram infectados com $\mathrm{CMV}$ e CMV+CPSMV-I. Esses resultados evidenciam que nesses genótipos, com a presença do CABMV associado ao CMV e também ao CMV+CPSMV-I, o efeito foi antagônico em relação aos outros vírus; em decorrência

Tabela 4. Sintomas apresentados pelos genótipos de feijão-caupi submetidos à inoculação mecânica com os vírus CMV, CMV+CABMV, $\mathrm{CMV}+\mathrm{CPSMV}-\mathrm{I}$ e CMV+CABMV+CPSMV-I

\begin{tabular}{|c|c|c|c|c|}
\hline \multirow{2}{*}{ Genótipos } & \multicolumn{4}{|c|}{ Sintomas } \\
\hline & CMV & CMV+CABMV & CMV+CPSMV-I & CMV+CABMV+CPSMV-I \\
\hline BR17- Gurguéia & Ss & $\mathrm{M}, \mathrm{BI}$ & Ss & Ml \\
\hline Epace V-96 & Ml & M & Ml & $\mathrm{M}, \mathrm{BI}$ \\
\hline Patativa & $\mathrm{Ml}$ & Ss & Ml & Ss \\
\hline TE97-309G-22 & $\mathrm{Ml}$ & Ss & Ml & Ss \\
\hline TE97-309G-9 & Ml & Ss & Ml & Ss \\
\hline TVu 379 & Ml & Ml & Ml & Ml \\
\hline TVu 382 & Ml & Ss & Ml & $\mathrm{Ml}$ \\
\hline TVu 3961 & Ml & M & M & $\mathrm{M}, \mathrm{BI}$ \\
\hline Tvu 966 & Ss & Ss & Ss & Ml \\
\hline CNC-0434 & Ml & $\mathrm{M}, \mathrm{BI}$ & Ml & $\mathrm{M}, \mathrm{BI}$ \\
\hline IT85F-2687 & Ml & Ss & Ms, Bl, Rf, Lc, Ma & $\mathrm{M}, \mathrm{BI}, \mathrm{Lc}, \mathrm{Ne}, \mathrm{Mt}$ \\
\hline TE97-200-49F & $\mathrm{Ml}$ & M & Ms, Lc, Rf & $\mathrm{M}, \mathrm{BI}, \mathrm{Lc}, \mathrm{Ne}, \mathrm{Mt}$ \\
\hline TVu 410 & Ss & M & Ms, BI, Rf & $\mathrm{M}, \mathrm{BI}, \mathrm{Lc}, \mathrm{Ne}, \mathrm{Mt}$ \\
\hline IT93K-452-1 & $\mathrm{Ml}$ & Ms, Bl, Rf & Ms, Lc, Rf & $\mathrm{M}, \mathrm{BI}, \mathrm{Lc}, \mathrm{Ne}, \mathrm{Mt}$ \\
\hline IT99K-1060 & Ml & $\mathrm{M}, \mathrm{BI}$ & Ms, Lc, Rf & $\mathrm{M}, \mathrm{BI}, \mathrm{Lc}, \mathrm{Ne}, \mathrm{Mt}$ \\
\hline Pampo & Ml & $\mathrm{Ms}, \mathrm{BI}$ & Ms, BI & $\mathrm{Ms}, \mathrm{Lc}, \mathrm{Ne}$ \\
\hline TE97-309G-24 & Ss & M & Ss & $\mathrm{M}, \mathrm{BI}$ \\
\hline BRS-Pajeú & Ml & $\mathrm{M}, \mathrm{BI}$ & M & $\mathrm{M}, \mathrm{BI}, \mathrm{Lc}, \mathrm{Ne}, \mathrm{Mt}$ \\
\hline
\end{tabular}

M: Mosaico. Ml: Mosaico leve. Ms: Mosaico severo. Bl: Bolhosidade. Lc: Lesăo clorótica. Rf: Reduçấo foliar. Ne: Necrose. Ma: Morte apical. Ss: Sem sintoma. 
Tabela 5. Médias da proporção de plantas assintomáticas, comprimento de vagem, número de grãos por vagem, massa de cem grãos e produtividade de 18 genótipos de feijão-caupi submetidos à infecção viral natural por vírus, em condição de campo

\begin{tabular}{|c|c|c|c|c|c|}
\hline Genótipos & $\begin{array}{c}\text { PPA }{ }^{(1)} \\
(\%)\end{array}$ & $\begin{array}{l}\text { COMPV } \\
(\mathrm{cm})\end{array}$ & $\begin{array}{l}\text { NGV } \\
\text { (unid.) }\end{array}$ & $\begin{array}{l}\text { M100G } \\
\text { (g) }\end{array}$ & $\begin{array}{c}\text { PROD } \\
{\left[\mathrm{g}\left(4 \mathrm{~m}^{2}\right)^{-1}\right]}\end{array}$ \\
\hline BRS-Pajeú & $1,21 \mathrm{~A}$ & $18,78 \mathrm{~A}$ & $14,30 \mathrm{~B}$ & $18,78 \mathrm{C}$ & 535,59 A \\
\hline TE97-309G-9 & $1,37 \mathrm{~A}$ & $16,41 \mathrm{~B}$ & $13,40 \mathrm{~B}$ & $18,67 \mathrm{C}$ & $497,00 \mathrm{~A}$ \\
\hline BR17-Gurguéia & $0,47 \mathrm{~B}$ & $16,63 \mathrm{~B}$ & $14,25 \mathrm{~B}$ & $13,65 \mathrm{~F}$ & $471,33 \mathrm{~A}$ \\
\hline TVu 410 & $1,17 \mathrm{~A}$ & $17,35 \mathrm{~B}$ & $18,65 \mathrm{~A}$ & $8,60 \mathrm{H}$ & $432,75 \mathrm{~A}$ \\
\hline Patativa & $1,27 \mathrm{~A}$ & $16,35 \mathrm{~B}$ & $12,60 \mathrm{~B}$ & $18,40 \mathrm{C}$ & $416,90 \mathrm{~A}$ \\
\hline TE97-309G-24 & $0,89 \mathrm{~A}$ & $17,47 \mathrm{~B}$ & $14,15 \mathrm{~B}$ & $20,15 \mathrm{~B}$ & $411,16 \mathrm{~A}$ \\
\hline Epace V-96 & $0,69 \mathrm{~B}$ & $15,46 \mathrm{C}$ & $13,10 \mathrm{~B}$ & $14,66 \mathrm{E}$ & 370,79 B \\
\hline TE97-200-49F & $1,08 \mathrm{~A}$ & $20,02 \mathrm{~A}$ & $13,70 \mathrm{~B}$ & $19,05 \mathrm{C}$ & 335,93 B \\
\hline TE97-309G-22 & $0,91 \mathrm{~A}$ & $19,14 \mathrm{~A}$ & $13,20 \mathrm{~B}$ & $19,70 \mathrm{~B}$ & $329,63 \mathrm{~B}$ \\
\hline IT99K-1060 & $0,84 \mathrm{~A}$ & $14,09 \mathrm{D}$ & $10,25 \mathrm{C}$ & $20,78 \mathrm{~A}$ & $303,60 \mathrm{~B}$ \\
\hline IT85F-2687 & $1,50 \mathrm{~A}$ & $13,31 \mathrm{D}$ & $9,70 \mathrm{C}$ & $16,21 \mathrm{D}$ & $247,80 \mathrm{C}$ \\
\hline IT93K-452-1 & $0,60 \mathrm{~B}$ & $14,81 \mathrm{C}$ & $10,40 \mathrm{C}$ & $18,83 \mathrm{C}$ & $208,83 C$ \\
\hline TVu 379 & $1,02 \mathrm{~A}$ & $14,32 \mathrm{D}$ & $14,45 \mathrm{~B}$ & $9,40 \mathrm{G}$ & $165,65 \mathrm{C}$ \\
\hline CNC-0434 & $0,35 \mathrm{~B}$ & $15,72 \mathrm{C}$ & $13,40 \mathrm{~B}$ & $16,08 \mathrm{D}$ & $137,85 \mathrm{C}$ \\
\hline TVu 382 & $1,03 \mathrm{~A}$ & $14,70 \mathrm{C}$ & $14,20 \mathrm{~B}$ & $9,90 \mathrm{G}$ & $136,38 \mathrm{C}$ \\
\hline TVu 966 & $0,95 \mathrm{~A}$ & $17,03 \mathrm{~B}$ & $12,65 \mathrm{~B}$ & $13,99 \mathrm{~F}$ & $51,00 \mathrm{D}$ \\
\hline TVu 3961 & $0,30 \mathrm{~B}$ & $7,28 \mathrm{E}$ & $7,70 \mathrm{D}$ & 5,201 & $15,75 \mathrm{D}$ \\
\hline Pampo & $0,87 \mathrm{~A}$ & $0,00 \mathrm{~F}$ & $0,00 \mathrm{~F}$ & $0,00 \mathrm{~J}$ & $3,48 \mathrm{D}$ \\
\hline
\end{tabular}

Médias na vertical seguidas de mesma letra maiúscula não diferem pelo teste de Scoott-Knott a ( $>00,05)$. ( $\left.{ }^{1}\right)$ Dados transformados para arcsen $\sqrt{ } \mathrm{x}$. PPA: porcentagem de plantas assintomáticas. COMPV: Comprimento de vagem. NGV: número de grăos por vagem. M100G: Massa de cem grãos. PROD: produtividade.

desse fato, não houve sintomas quando infectados com citadas combinaçôes virais. Porém, avaliando-se o comportamento dos dezoito genótipos diante das inoculações com os diferentes grupos de isolados virais, constatou-se que houve coerência de comportamento, principalmente nas inoculaçôes mistas, ocorrendo sintomas leves nos mais resistentes, e nos mais suscetíveis, um agravamento dos sintomas das infecções mais simples para as complexas.

\section{Ensaio em campo sob infecçáo natural}

No caráter porcentagem de plantas assintomáticas, destacaram-se os genótipos IT85F-2687, TE97-309G-9, Patativa, BRS Pajeú e TVu 410. No caráter comprimento de vagem foram formados seis grupos. Nos genótipos TE97-200-49F, TE97-309G-22 e BRS-Pajeú com vagens com $20,02 \mathrm{~cm}, 19,14 \mathrm{~cm}$ e $18,78 \mathrm{~cm}$, respectivamente, as maiores médias foram observadas para esse caráter. Para o número de grãos por vagem, os genótipos foram distribuídos em seis grupos, ficando a maioria no grupo B. O genótipo TVu 410 foi o de maior valor para esse caráter com média de 18,65 grãos por vagem. No caráter massa de cem grãos, os genótipos foram divididos em dez grupos. A maior média foi verificada no genótipo IT99K-1060 (20,78 g). Os genótipos BRS-Pajeú, TE97-309G-9, BR17-Gurguéia, TVu 410, Patativa e TE97-309G-24 tiveram os melhores desempenhos para produtividade de grãos. Houve certa correspondência entre o caráter porcentagem de plantas assintomáticas e produtividade para os genótipos TE97-309G-9, Patativa, BRS-Pajeú, TVu 410, TE97-309G-24. Entretanto, com a cultivar BR17-Gurguéia essa correspondência não ocorreu. Ao contrário das outras, houve baixo índice de plantas sem sintomas (Tabela 5).

\section{CONCLUSÃO}

Houve diferença entre genótipos nas infecçôes com CMV, CMV+CABMV, CMV+CPSMV-I e $\mathrm{CMV}+\mathrm{CABMV}+\mathrm{CPSMV}-\mathrm{I}$. Os genótipos com o melhor comportamento diante das infecçóes controladas com CMV, CMV+CABMV, CMV+CPSMV-I e $\mathrm{CMV}+\mathrm{CABMV+CPSMV-I}$ foram BR17-Gurguéia, Epace V-96, Patativa, TE97-309G-9, TE97-309G-22, TE97-309G-24, TVu 379, TVu 382, TVu 966 e TVu 3961. Os genótipos BR17-Gurguéia, Epace V-96, TE97309G-9, TE97-309G-22, TE97-309G-24 e Patativa têm boa produtividade e sementes com características de padrão comercial, portanto, podem ser usados diretamente em programa de melhoramento. Já os genótipos TVu 379, TVu 382, TVu 966 e TVu 3961, com grãos muito pequenos, estão fora do padrão comercial, portanto, há necessidade de pré-melhoramento antes de serem incluídos em um programa de melhoramento.

\section{AGRADECIMENTOS}

A primeira autora agradece à Coordenação de Aperfeiçoamento de Pessoal de Nível Superior-CAPES, pela concessão da bolsa de estudo. 


\section{REFERÊNCIAS}

BARRETO, P.D.; SANTOS, A.A. Avaliação de Genótipos de Feijão-de-Corda sob infecção simultânea por "Cowpea aphid-borne mosaic virus" e "Cucumber mosaic virus". Fortaleza: EmbrapaCNPAT, 1999.

BESERRA JUNIOR, J.E.A.; ANDRADE, E.C.; CAMARÇO, R.F.R.A.; NASCIMENTO, A.K.Q.; LIMA, J.A.A. Sequence variability in the coat protein gene of Cowpea severe mosaic vírus isolates from northeastern Brazil. Tropical Plant Pathology, v.36, p.121-124, 2011.

CRUZ, C.D. Programa genes. Aplicativos computacional em Genética e Estatística. www.Ufv.br/dbg/genes.htm versão 2007.

GARCÍA-CANO, E.; RESENDE， R.O.; FERNÁNDEZMUNOOZ, R.; MORIONES, E. Synergistic interaction between Tomato chlorosis vírus and Tomato spotted wilt vírus results in breakdown of resistance in tomato. Phytopathology, v.96, p.1263$1269,2006$.

GUERINI, M.N.; MURPHY, J.F. Resistance of Capsicum annuum 'Avelar' to pepper mottle potyvirus and alleviation of this resistance by co-infection with cucumber mosaic cucumovirus are associated are associated with virus movement. Journal of General Virology, v.80, p.2785-2792, 1999.

HULL, R. Matthew's. Plant Virology. 4. ed. San Diego: Academic Press, 2002. 1001p.

KAREEM, K.T.; TAIWO, M.A. Interactions of viruses in cowpea: effects on growth and yield parameters. Virology Journal, v.4, p. 1-7, 2007.

KARYEIJA, R.F.; KREUSE, J.F.; GIBSON, R.W.; VALKONEN, J.P.T. Synergistic interactions of a potyvirus and a phloem-limited crinivirus in sweet potato plants. Virology, v.269, p.26-36, 2000.

LIMA, J.A.A.; SANTOS, C.D.G.; SILVEIRA, L.F.S. Comportamento de genótipos de Caupi em relação aos dois principais vírus que ocorrem no Ceará. Fitopatologia Brasileira, v.11, p.151-161, 1986.

LIMA, J.A.A.; SITTOLIN, I.M.; LIMA, R.C.A. Diagnoses e Estratégias de Controle de Doenças Ocasionadas por Vírus. In: FREIRE FILHO, F.R.; RIBEIRO, V.Q.; LIMA, J.A.A.; SILVA, P.H.S. (Ed.). Feijão-caupi: Avanços Tecnológicos. 1.ed. Brasília: Embrapa Informaçóes Tecnológicas, 2005. p.405-459.

LIN, M.T.; KITAJIMA, E.W.; RIOS, G.P. Serological identification of several cowpea viruses in central Brazil. Fitopatologia Brasileira, v.6, p.73-85, 1981a.

LIN, M.T.; SANTOS, A.A.; KITAJIMA, E.W. Host reactions and transmission of two seed-borne cowpea viruses from central Brazil. Fitopatologia Brasileira, v.6, p.193-203, 1981 b.

MARTÍN, S.; ELENA, S.F. Application of game theory to the interaction between plant viruses during mixed infections. Journal of General Virology, v.90, p.2815-2820, 2009.
MIH, A.M.; ATIRI, G.I.; THOTTAPPILLY, G. Relationships between co-infection with Cowpea aphid-borne and Cucumber mosaic virus and yield of cowpea lines with resistance to these viruses. Phytoparasitica, v.19, p.65-72. 1991.

MURPHY, J.F.; BOWEN, K.L. Synergistic disease in pepper caused by mixed infection of cucumber mosaic virus and pepper mottle virus. Phytopathology, v.96, p.240-247, 2006.

PIO-RIBEIRO, G.; WYATT, S.D.; KUHN, C.W. Cowpea Stunt: A disease caused by a synergistic interaction of two viruses. Phytopathology, v.68, p.1260-1265. 1978.

PRUSS, G.; GE, X.; SHI, X.M.; CARRINGTON, J.C.; VANCE, V.B. Plant viral synergism: the potyviral genome encodes a broadrange pathogenicity enhancer that transactivates replication of heterologous viruses. Plant Cell, v.9, p.859-868, 1997.

ROCHA, M.M.; LIMA, J.A.A.; FREIRE FILHO, F.R.; ROSAL, C.J.S.; LOPES, A.C.A. Resistência de genótipos de Caupi (Vigna unguiculata L. Walp.) de tegumento branco a isolados de vírus das famílias Bromoviridae, Comoviridae e Potyviridae. Ciência Rural, v.8, p.85-92, 2003.

SANTOS, F.M.L.; LIMA, J. A.A.; SANTOS, A.A.; BARRETO, P.H. Infecçóes simples e múltiplas de vírus em caupi no Ceará. Fitopatologia Brasileira, v.24, p.518-522, 1999.

SAS INSTITUTE (CARY, NC). SAS/STAT: User's guide, version 8.1. Cary 2000. v.1. 943p.

SYLLER, J. Facilitate and antagonistic interactions between plant viruses in mixed infections. Molecular Plant Pathology. Review. v.12, p.1-13, 2011.

TAIWO, M.A.; KAREEM, K.T.; NSA, I.Y.; HUGHES, J.D.A. Cowpea viruses: effect of single and mixed infections on symptomatology and virus concentration. Virology Journal, v.4, p.1-5, 2007.

VALE, C.C.; LIMA, J.A.A. Efeitos de infecção isoladas e mistas de vírus de grupos distintos em caupi. Fitopatologia Brasileira, v.19, p.193-197, 1994.

VOINNET, O. Induction and suppression of RNA silencing: insights from viral infections. Nature Reviews Genetics, v.6, p.206$220,2005$.

WANG, Y.; GABA, V.; YANG, J.; PALUKAITIS, P.; GAL-ON, A. Characterization of synergy between cucumber mosaic virus and potyviruses in cucurbit hosts. Phytopathology, v.92, p.51-58, 2002.

WANG, Y.; LEE, K.C.; GABA, V.; WONG, S.M.; PALUKAITIS, P.; GAL-ON, A. Breakage of resistance to cucumber mosaic virus by co-infection with zucchini yellow mosaic virus enhancement of $\mathrm{CMV}$ accumulation independent of symptom expression. Archives of Virology, v.149, p.379-396, 2004.

ZIMMERMANN, F.J.P. Estatística aplicada à pesquisa agrícola. 1.ed. Santo Antônio de Goiás. GO: Embrapa Arroz e Feijão, 2004. 402p. 